\title{
Human-dog relationships as a working framework for exploring human-robot attachment: a multidisciplinary review
}

\author{
Frank Krueger ${ }^{1,2,3,4}$ (1) $\cdot$ Kelsey C. Mitchell ${ }^{1} \cdot$ Gopikrishna Deshpande ${ }^{5,6,7,8,9,10} \cdot$ Jeffrey S. Katz ${ }^{5,6,7,8}$
}

Received: 15 September 2020 / Revised: 16 December 2020 / Accepted: 2 January 2021 / Published online: 24 January 2021

(c) The Author(s), under exclusive licence to Springer-Verlag GmbH, DE part of Springer Nature 2021

\begin{abstract}
Robotic agents will be life-long companions of humans in the foreseeable future. To achieve such successful relationships, people will likely attribute emotions and personality, assign social competencies, and develop a long-lasting attachment to robots. However, without a clear theoretical framework-building on biological, psychological, and technological knowledge-current societal demands for establishing successful human-robot attachment (HRA) as a new form of inter-species interactions might fail. The study of evolutionarily adaptive animal behavior (i.e., ethology) suggests that human-animal behaviors can be considered as a plausible solution in designing and building models of ethorobots_including modeling the inter-species bond between domesticated animals and humans. Evidence shows that people assign emotional feelings and personality characteristics to animal species leading to cooperation and communication—crucial for designing social robots such as companion robots. Because dogs have excellent social skills with humans, current research applies humandog relationships as a template to understand HRA. Our goal of this article is twofold. First, we overview the research on how human-dog interactions are implemented as prototypes of non-human social companions in HRA. Second, we review research about attitudes that humans have for interacting with robotic dogs based on their appearance and behavior, the implications for forming attachments, and human-animal interactions in the rising sphere of robot-assisted therapy. The rationale for this review is to provide a new perspective to facilitate future research among biologists, psychologists, and engineers-contributing to the creation of innovative research practices for studying social behaviors and its implications for society addressing HRA.
\end{abstract}

Keywords Attachment $\cdot$ AIBO $\cdot$ Dog $\cdot$ Social robotics $\cdot$ Ethorobotics $\cdot$ Uncanny valley

Frank Krueger

fkrueger@gmu.edu

1 School of Systems Biology, George Mason University, Fairfax, VA, USA

2 Department of Psychology, George Mason University, Fairfax, VA, USA

3 Institute for Biohealth Innovation, George Mason University, Fairfax, VA, USA

4 Center for Adaptive Systems of Brain-Body Interactions, George Mason University, Fairfax, VA, USA

5 Department of Electrical and Computer Engineering, AU MRI Research Center, Auburn University, Auburn, AL, USA
6 Department of Psychological Sciences, Auburn University, Auburn, AL, USA

7 Center for Neuroscience, Auburn University, Auburn, AL, USA

8 Alabama Advanced Imaging Consortium, Birmingham, AL, USA

9 Key Laboratory for Learning and Cognition, School of Psychology, Capital Normal University, Beijing, China

10 Department of Psychiatry, National Institute of Mental Health and Neurosciences, Bengaluru, India 


\section{Ethorobotics: a promising path to model human-robot attachment}

\section{Social robotics and the "uncanny valley" hypothesis}

The latest advances in parallel and distributed computing have led to significant efforts in investigating human robot interaction (HRI). These advances have created a burgeoning and more sophisticated focus on human-robot attachment (HRA). Specifically, researchers and engineers design and build mobile, autonomous robots as social actors who are capable of a wide array of social behaviors in therapeutic, educational, and entertainment environments (Dautenhahn 2007; Fong et al. 2003). Social robots include the following three key dimensions as vital factors for HRIs: anthropomorphism, emotion, and personality (Fong et al. 2003). The employment of anthropomorphic elements utilized in the form of face-shaped objects or human-like speech (Baron-Cohen et al. 1995; Cooper and Aslin 1990; Duffy 2003; Fernald 1992), the recognition and manifestation of internal emotional states based on verbal and non-verbal indicators (Brooks 2002), and the expression of a captivating personality materialized as physical attributes, motion patterns, and communication styles (Breazeal and Aryananda 2002; Kiesler and Goetz 2002) trigger a natural evolutionarily human response (Bloom and Veres 1999; Dautenhahn and Werry 2004; Heider and Simmel 1944). Human-likeness mimics the embodiment, and social interaction can be implemented in various types of "human-like" robots (Kanda et al. 2009; MacDorman and Ishiguro 2006): humanoids aim to resemble the human's posture and fundamental anatomy (although still representing a machine-like appearance); androids aim to represent a detailed copy of a human's body (e.g., application of human-like skin); and geminoids aim to display duplicates of real people (Becker-Asano et al. 2010). However, there is more than one approach to robotic design. In this review, we provide a new perspective to facilitate future research among biologists, psychologists, and engineers-contributing to the creation of innovative research practices for studying social behaviors and its implications for society addressing HRA. In doing so, we begin with discussing the exciting new discipline of ethorobotics. Next, we tie in how companion dogs can serve as the guiding relationship for future research. We then review research on the ethorobotic dog AIBO and how AIBO has been used in animal-assisted therapy. We conclude with the current outlook and future directions for HRA with social robots.

Ethology - the scientific study of animal behavior seen as evolutionarily adaptive traits-focuses on the purpose of behavior linked to the precise natural settings throughout the evolution of a species (Miklósi et al. 2017; Tinbergen 1963). Ethorobotics is a relatively new concept originated by Miklosi and colleagues based on recent progress in HRI that integrates ethological, ecological, and evolutionary principles toward the development of social robots (Miklósi et al. 2017). In essence, ethorobotics facilitates the application of the biological rules of animal behavior to build new interactive robotic systems. Ethorobotics was inspired by the "uncanny valley" (Miklósi et al. 2017; Mori 1970). When social robots are created to fully act as "human-like" actors-but are still not quite perfect - their subtle imperfections can cause dismay and evoke revolt from users-a phenomenon recognized as "uncanny valley" (Mori 1970) or the "zombie effect" (Dautenhahn et al. 2002; Fong et al. 2003). Describing the relationship between human affinity toward the (biological or artificial) agent and an agent's human similarity, social robotics develops in time-i.e., from left to right having two local maximum values-to design human-like robots (i.e., human likeness) (Fig. 1) (Miklósi et al. 2017). The medium peak occurs when robotic agents have a sufficient but not entire similarity (60-75\%) to humans, while the maximum peak arises when robotic agents reach nearly perfect similarity to humans (Mori 1970). The "uncanny valley" hypothesis proposes that social robots may never reach the "maximum peak" (i.e., ideal humanness) because robots getting very similar to humans are being more rejected by users than less similar ones (Mori, 1970).

Instead of climbing the "maximum peak" for building more human-like robots, researchers can circumvent the "maximum peak"- preventing the "uncanny valley"-by creating social robots that are capable of maximizing their

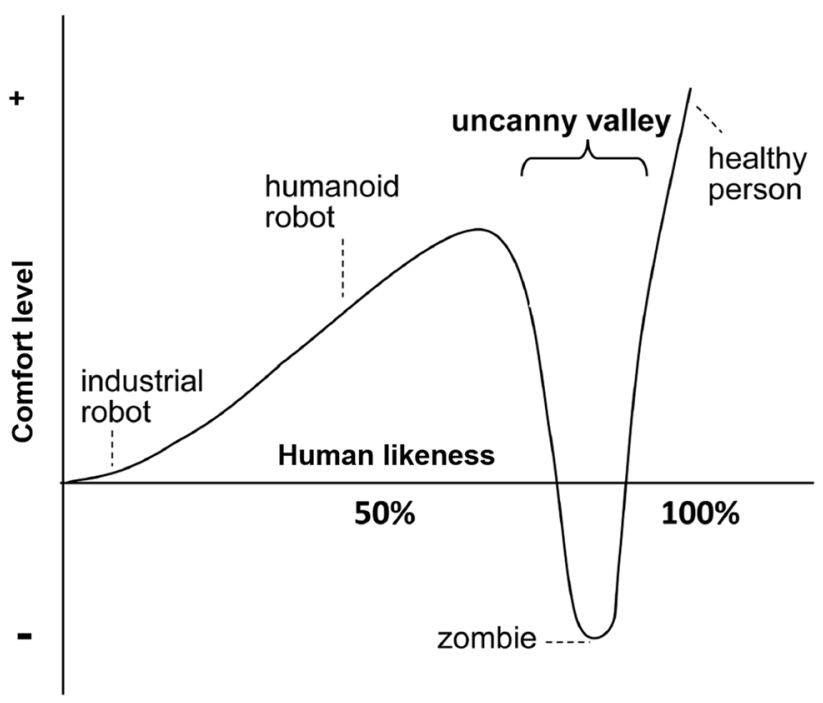

Fig. 1 'Uncanny valley' hypothesis [adjusted from (Miklósi et al. 2017)] 
performance for specific functions in its specific environments (Konok et al. 2018). When such ethorobots are equipped with specific functions concerning socio-cognitive and behavioral characteristics-e.g., functioning as an attached companion for individuals with limited caretaking capabilities and social interaction-then humans will approach them separately from its human resemblance (Pineau et al. 2003). Those ethological robots would occupy a different social niche, specific to its function, and evolve without competing with humans (Miklósi et al. 2017). Consequently, robotic engineering could advance by changing between different types of robotic agents without being restricted by the evolutionary continuity of human agents (Miklósi and Gácsi 2012).

Based on an ethological approach, shared interactions with other species during human history can provide behavioral prototypes for social robotic agents (Miklósi and Gácsi 2012). Hence, human-animal interactions can serve as plausible alternatives for human-like robots as models of social robotic agents (Korondi et al. 2015). HRIs based on interrather than intra-species relationships are less complex, and simpler to employ in social robots (Konok et al. 2018). An inter-species focus on a functional approach emphasizes the goal that robotic agents are not built for a social state per se but rather for a social process, such as attachment (Miklósi et al. 2017), where the relationship type is not a given feature of a robot but more a consequence of meaningful social interaction between agents (Fujita 2007; Miklósi and Gácsi 2012). This review will examine the foundation of using dog-human relationships as the inspiration for social robotic design and HRA.

\section{Dogs as prototypes for human-robot attachment}

Social behaviors in both non-humans and humans have evolved to contribute to the survival of the species (Székely et al. 2010). At the practical stage, social behaviors fulfill unique behavioral purposes and share some commonalities among distinct organisms because of changes in evolution (Fitch et al. 2010). Hence, social interactions can be characterized not only within but also between species (Colgan 1983; Miklósi and Gácsi 2012; Podberscek and Gosling 2000; Serpell et al. 1996). These interactions for humans may have arisen in communities of hunter-gatherers who came in contact with the infant offspring of the chased animals (Clutton-Block 1995).

While there has been multiple genetic studies regarding dog domestication, there is not yet a widely accepted time or location of domestication (Ostrander et al. 2019; von Holdt et al. 2010). The emergence of domesticated animals such as dogs and cats has led to companion animal-keeping habits in humans, which has grown immensely and shifted in purpose-likely resultant of the intensely social character of human beings (Irvine and Cilia 2017). For example, domesticated animals might have been one of the first opportunities for children to develop their nursing and caring abilities outside of the role of sibling caretakers (Hrdy 2000). Companion animals tend to be the best aspirant for modeling HRIs and HRA since they can establish positive human social experiences (Miklósi and Gácsi 2012).

Owners typically have long-lasting and personalized partnerships toward their animals, which is a goal of designing social robots. Companion animals contribute to socializing people who may have witnessed a decline in social interactions (e.g., sick people), been excluded from society (e.g., homeless people), or become lonely throughout their life (e.g., widowers) (Albert and Bulcroft 1988). Consequently, human-animal relationships could provide a useful nonhuman model for a wide variety of robots as companions (Bensky et al. 2013; Dautenhahn and Werry 2004; Korondi et al. 2015; Miklósi and Gácsi 2012; Morell 2009).

Dogs are the most popular companion animal among household animals; they encompass excellent social competence with humans because of a successful adaption to the human landscape (Kubinyi et al. 2007; Miklósi and Topál, 2013; Topál et al. 2009). Dog domestication induced some major anatomical, morphological, and behavioral changes, which improved social relationships with humans (Hare and Tomasello 2005; Miklósi 2014). Dogs' specific environments for contact with humans emerged during domestication, while both species retained their autonomous ability to adapt with minimal competition between them (Gácsi et al. 2013). Having specific preferences for recognizing humanbased signals (Hare and Tomasello 2005; Reid 2009), dog breeds were chosen for specific reasons, including assisting in human activities and helping disabled individuals (Gácsi et al. 2016; Miklósi 2014).

The evolved behavioral traits and behaviors have tightened social relationships, improved social communication, and enhanced cooperative interactions for human-dog relationships (Csányi 2000; Topál et al. 2009). Dogs can respond to gestural and auditory signals given by humans (Kaminski et al. 2009; Soproni et al. 2002), form human-like personalities (Gosling et al. 2003; Turcsán et al. 2012), and establish bonding partnerships (Gácsi et al. 2001; Valsecchi et al. 2010). Human beings can effectively identify emotional gestures (Bloom and Friedman 2013; Pongrácz et al. 2006; Walker et al. 2010), assign complex emotions (Hecht et al. 2012), and describe personalities to their canine companions (Gosling et al. 2003; Turcsán et al. 2012). Significantly, humans can form deep, long-term bonds with their dogs (Archer and Ireland 2011) — often considering them as members of their family (Berryman et al. 1985; Kubinyi et al. 2009).

The bond between a human infant and the child's caregiver is typically described as attachment-fulfilling an 
evolutionary function (e.g., parental care) (Bowlby 1972; Fraley and Roberts 2005; Immerman and Mackey 2003). These attachment relationships from childhood continuously enrich human life through adulthood and are characterized by specific behaviors, including protest and avoidance of feelings of social isolation in challenging situations. Dogs may also form a bond with their owners, behaviorally similar to that between the child and the caregiver, including seeking protection in case of danger, increased demand for communication, and protest when being separated from the owner (Gácsi et al. 2001; Prato-Previde et al. 2003; Topál et al. 1998).

In recent times, the attachment concept has likewise been applied to HRI. In the near future, people will also live with social robots as long-term companions; therefore, they have to accept and see them as social partners capable of emotionally bonding. In the setting of HRI, bonding can be regarded as the amount of a user's emotional interactions with a robot within three dimensions: visceral level (e.g., first-time impression through appearance), behavioral level (e.g., satisfaction of the robot's features for the user), and reflective level (e.g., recall past experiences and utilize them for future actions) (Birnbaum et al. 2016; Herath et al. 2013). Using a dog model can generate emotional expressions without adding unique, otherwise non-functional features to social robots (Gácsi et al. 2016). These ethorobots should effectively carry out behaviors appropriate for their particular purpose (e.g., helping elderly people and people with disabilities) and show credible communicative skills when cooperating with humans-a skill set found in dogs (Miklósi et al. 2017). These similarities between humans and robots regarding social skills-openness to learn (Topál et al. 2009), interactive communication (Gaunet and Massioui 2014; Miklósi and Gácsi 2012), and social attachment (Topál et al. 2005)—should be adequate to form a foundation for social interaction and future attachment.

The dog has been effectively incorporated in HRI studies as a model for non-human companions (Ichikawa et al. 2012; Koay et al. 2013; Kovács et al. 2009; Lakatos et al. 2014; Syrdal et al. 2010). For example, a robot was built using a Roomba vacuum cleaner system that represented a crudely canine entity (e.g., fitted with a tail and capable of making barking sounds) and exhibited certain dog-like behavioral traits while interacting with people (Jones et al. 2008). Other research has been published on a blind-guide-dog-inspired robot (Tachi et al. 1985) or a robot designed to help disabled individuals (Nguyen et al. 2008). In the former investigation, the embodiment of the robot did not mimic a dog but used an arm for actions (that could be controlled verbally) that the dog typically does by mouth.

In summary, robotics strives to produce social robots that fulfill users' needs, but modern society does not embrace today's robots due to their restricted skills that undermine their human-like nature (Mori 1970). The emerging field of ethorobotics provides a different approach, proposing that social robots should be treated as distinct organisms highly suited to their environment, in which their human similarity is insignificant (Miklósi et al. 2017). Ethorobots provide several advantages for human society. No reasons exist to compete with ethorobots as human agents can retain power by manipulating the essence of the relationship. People have the required abilities to adapt their social interactions to robots if those exhibit simple social skills and form attachments as they do with companion animals due to their similar social skill levels.

As one of these ethorobots, this review will highlight Sony's AIBO as a protype for HRA. While AIBO is physically inspired by dogs, its embodiment is of secondary importance in terms of ethorobotics. AIBO's ability to fulfill the purpose of social companionship via both non-verbal dog-like communication and non-dog-like behaviors is key to its definition as an ethorobot (Abdai et al. 2018).

\section{AIBO}

\section{Sony's AIBO-a prototype for human-robot attachment}

The next type of autonomous entertainment robot is primarily built to interact with humans that have the propensity to provoke attachment (Donath 2004; Kaplan 2001). Other types of autonomous robots act as educators for children (Billard 2003), museum-guides for visitors (Nourbakhsh et al. 1999; Burgard et al. 1999), and co-therapists for patients (Dautenhahn et al. 2002). The release of these commercial robots supports the assumption that they soon could become common in our everyday environments. This forecast has prompted some studies into the acceptability and perspectives these types of robots produce among human beings (Fong et al. 2003). A new technological category is on the horizon-embodied, autonomous, and personified robots-that will contradict conventional ontological distinctions between animate and inanimate.

Robots are classified as 'zoomorphs' if they mimic live, current, or imaginary animals. For instance, one of the earliest 'electric dogs' - i.e., radio-controlled robot representing a box rolling on three wheels-was built in 1912. Since then, several high-profile social robotics companies aim at designing and selling social robots specifically intended to serve as long-term companions. These robots-including Paro, Kaspar, the 'Joy for all' robotic pet line, Pepper, and Jibo-are designed with either therapeutic or companionship benefits in mind. Most of them do not fulfill the description of an ethorobot by either physical manifestation or sophistication of communication (Émond et al. 2020; Schrum et al. 2019; 
Thunberg et al. 2020; Wada et al. 2010; Wood et al. 2019). One of the most advanced robots of this type entails Sony's dog-like robot $A I B O$ - an acronym for Artificial Intelligence roBOt-meaning in Japanese language "friend," "pal," or "companion" (www.sony.com). Introduced in 1999 for the commercial market, until 2006, more than 150,000 robots were sold worldwide over 3 successive AIBO generations (consisting of 8 versions with 23 subtypes). However, Sony discontinued AIBO's production in 2006 and stopped software updates and maintenance in 2014. After years of redesigning, Sony commercially released the fourth generation of the AIBO Entertainment Robot in 2018-designed to be the most advanced "autonomous robot" dog available and commercialized as a "perfect partner with true emotion and intuition" (Fig. 2).

AIBO's behavior is specifically modeled after dog behavior (Arkin 2001) — based on an ethologist-promoted behavioral method approach (Tinbergen 1951; Timberlake 1994). AIBO mimics a small dog's body-including a dog-like metallic architecture with flexible body parts as well as a set of sensors (i.e., microphone, camera, touch sensors) - that allows users to interact by discriminating punitive strokes from affectionate pats. Besides having a movable tail, head, and ears to express dog-like behaviors, AIBO's two expressive OLED eyes display inner mental states to its face, and varying sounds express tiredness, frustration, or enthusiasm. The user can interact with AIBO in two ways: through voice commands and pressure sensors. AIBO has speech recognition, executes about 30 commands given per voice (e.g., sit, lie down, and turn), and takes digital pictures with a camera located in the nose. AIBO recognizes its name after being recorded and responds with computerized sounds when named.

AIBO can sit or lie down, get up, or walk similarly to a real dog. It can further be taught to perform basic behaviors (Kaplan et al. 2002) and is able to learn after experiencing unfamiliar situations (Oudeyer et al. 2005). AIBO is a lifetime companion-through its technological infrastructure-it evolves slowly from a puppy, adolescent, to a fully grown adult dog. Although it is autonomous, the combination of AIBO's behavior and interaction with his owner produces its personality and facilitates attachment-no two AIBOs are ever alike. Via repeated touch, AIBO learns to avoid (repeat) actions that have been punished with a brief and robust strokes. AIBO cannot only initiate dog-like interactions with humans (e.g., offering its paw) but can also change its future actions based on human feedback. Finally, the new AIBO generation can store and expands its 'mind' into the cloud, and hence, can also be operated and played with remotely (Knox and Watanabe 2018).

Because of these capacities, AIBO has been utilized in many research projects with two general research agendas: (1) questionnaires exploring if people consider AIBO as a "real" companion animal and the feelings allocated to this robotic dog and (2) observation of HRI based on behavior analyses (Bartneck et al. 2007; Friedman et al. 2003; Kahn Jr et al. 2002; Kertész and Turunen 2019; Melson et al. 2005). The design of AIBO incorporates key components of dog-human interaction and dog-like communication as a framework for human-robot attachment. By imitating a dog-human relationship, which is behaviorally similar to that of a human-child relationship, AIBO is able to access built-in biological and emotional responses to its behavior. Indeed, the schemata by which this ethorobot makes choices is dependent on sensor activation, previously activated schemata, and emotion, instincts, and user expectation (Kaplan et al. 2002). These schemata are organized into hierarchical trees and are activated in terms of general goals (Kaplan et al. 2002). This aligns at the very least with human expectation of dog decision-making (Kaminski et al. 2009; Kosfeld et al. 2005; Marshall-Pescini et al. 2012; Sanders 1993; Turcsán et al. 2015).

\section{Studies investigating attitudes and behavioral interactions with AIBO}

Assuming that autonomous social robots will inhabit human beings' daily living space as attached heterospecifics in the
Fig. 2 Sony AIBO. Fourth (current) generation (a) and first to third generations (b) (adjusted from Kertész and Turunen 2019)

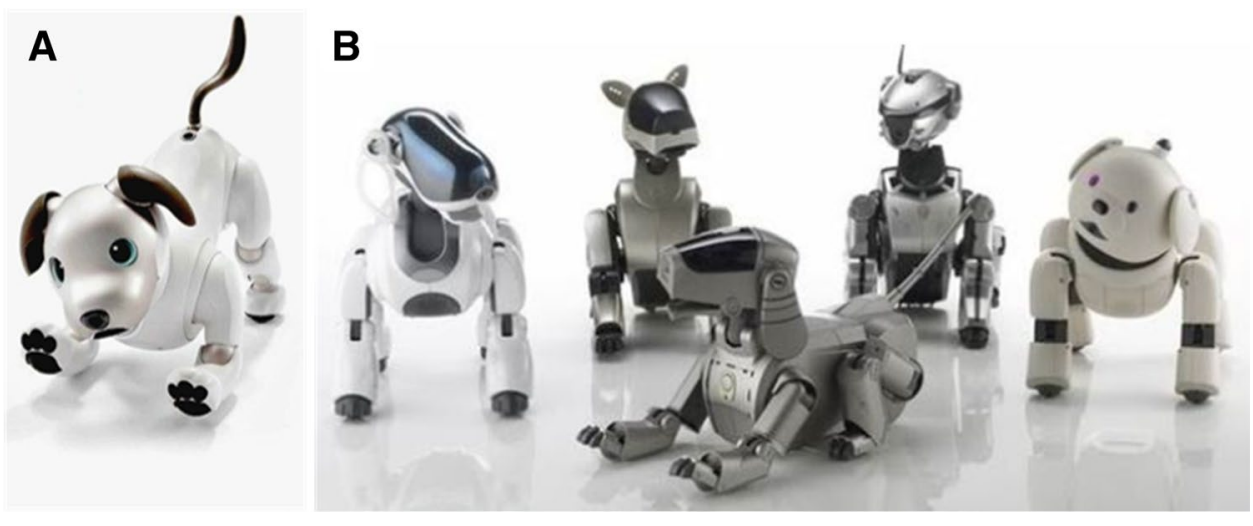


foreseeable future, it is crucial to investigate the human attitude toward interacting with a diverse range of robots founded on how they are received and communicate. Contrasting people's beliefs regarding robotic dogs and live dogs, most customers will not buy a companion animal robot because they believe that robots cannot be enjoyed as dogs are- being able to express emotions, personality, and attachment (Konok et al. 2018). Numerous research investigations concentrate on surveys from children or adults engaging with AIBO (as opposed to actual or stuffed dogs) and how both groups perceive and attribute social and ethical stances as well as ascribe emotions and attachment to the robotic dog. Besides investigating attitudes about AIBO, behavioral analysis of HRIs can help in inventing interactive robots because the chronological sequence of interaction is a reliable predictor of the ascribed attitudes and the potential for attachment (Table 1).
An online analysis of discussion-forum posts showed that AIBO psychologically engages its adults' owners as seen by ascribing $49 \%$ life-like essences, $59 \%$ social rapport, $60 \%$ mental states, and $75 \%$ technological essences (Friedman et al. 2003). Users neither think that AIBO is alive nor ascribe moralistic aspects to it, even if they assign social, psychological, and biological characteristics to the robotic dog. In contrast, interviews about AIBO revealed that although children distinguish the live from the robotic dog, they still ascribe mental, emotional, and moral characteristics to the robotic companion animal (Melson et al. 2005). Other research reveals that although children agree that anthropomorphic toys with different levels of interactivity are not realistic, they regard more interactive toys (including AIBO) as having actual and deliberate qualities (Francis and Mishra 2009). Moreover, independent of both the look and the behavior of the robots, younger children

Table 1 Studies investigating human attitudes and/ or behavioral interactions with the robotic dog AIBO

\begin{tabular}{|c|c|c|c|c|c|}
\hline Study & Participants & Exposure & AIBO Model & Control & Measure \\
\hline Bartlett et al. (2004) & $\begin{array}{l}\text { Children: } n=242, \\
\text { 3-10 years }\end{array}$ & $1(30-60 \mathrm{~min})$ & ERS-210+ ball & No control & $\begin{array}{l}\text { Video/audio, observa- } \\
\text { tion }\end{array}$ \\
\hline $\begin{array}{l}\text { Francis \& Mishra } \\
\quad(2009)\end{array}$ & $\begin{array}{l}\text { Children: } n=25(9 \mathrm{~F}) \text {, } \\
\text { 3-8 years }\end{array}$ & $12(10-31 \mathrm{~min})$ & N/A & $\begin{array}{l}\text { Stuffed dog, Mechani- } \\
\text { cal cat }\end{array}$ & Video \\
\hline Friedman et al. (2003) & Adults: $n=6438$ & N/A & $\begin{array}{l}\text { ERS-110/111, ERS- } \\
210\end{array}$ & N/A & $\begin{array}{l}\text { Online discussion-forum } \\
\text { postings }\end{array}$ \\
\hline Fujita (2004) & $\begin{array}{l}\text { Adults: } \\
\qquad n \sim 4000,>20-60 \text { years }\end{array}$ & N/A & $\begin{array}{r}\text { ERS-110/111, ERS- } \\
210, \text { ERS-311/312 }\end{array}$ & N/A & $\begin{array}{l}\text { Online discussion-forum } \\
\text { posting }\end{array}$ \\
\hline Kahn et al. (2006) & $\begin{array}{l}\text { Children: } n=80(40 \mathrm{~F}) \text {, } \\
\text { 3-6 years }\end{array}$ & $1(\sim 15 \mathrm{~min})$ & ERS-210 & No, stuffed dog used & Video/audio, questions \\
\hline Kerepesi et al. (2006) & $\begin{array}{l}\text { Children: } n=28(14 \mathrm{~F}) \text {, } \\
\text { 6-8 years } \\
\text { Adults: } n=28(14 \mathrm{~F}) \text {, } \\
\text { 18-22 years }\end{array}$ & $1(5 \min )$ & ERS-210+ ball & Dog puppy & Video (Themecoder) \\
\hline $\begin{array}{l}\text { Kertész and Turunen } \\
\text { (2019) }\end{array}$ & Adults: $n=78(19 \mathrm{~F})$ & N/A & N/A & N/A & Online questionnaire \\
\hline Lee et al. (2005) & $\begin{array}{l}\text { Adults: } n=40(20 \mathrm{~F}) \text {, } \\
\text { 19-24 years }\end{array}$ & $4(30 \mathrm{~min})$ & N/A & N/A & Questionnaire \\
\hline Melson et al. (2009) & $\begin{array}{l}\text { Children: } n=72 \text {, } \\
7-15 \text { years }\end{array}$ & $1(5 \mathrm{~min})$ & ERS-210 & Large-sized dog & Video/audio, Interview \\
\hline $\begin{array}{l}\text { Okita \& Schwartz } \\
\text { (2006) }\end{array}$ & $\begin{array}{l}\text { Children: } n=32 \text {, } \\
3.5-5.5 \text { years }\end{array}$ & $1(10-15 \mathrm{~min})$ & $\begin{array}{l}\text { ERS-210, ERS-220A, } \\
\text { ERS-311 }\end{array}$ & No control & Video/audio, questions \\
\hline Pepe et al. (2008) & $\begin{array}{l}\text { Adults: } n=29(20 \mathrm{~F}) \text {, } \\
18-45 \text { years }\end{array}$ & 1 & ERS-7 & Small-sized dog & Audio \\
\hline Ribi et al. (2008) & $\begin{array}{l}\text { Children: } n=14(6 \mathrm{~F}) \text {, } \\
\text { 3-6 years }\end{array}$ & $11(5 \mathrm{~min})$ & ERS-210+ ball & Small-sized dog & Observation \\
\hline Schellin et al. (2020) & $\begin{array}{l}\text { Adults: } n=33(12 \mathrm{~F}) \text {, } \\
18-26 \text { years }\end{array}$ & $1(10 \min )$ & ERS-1000 & AIBO in fur suit & $\begin{array}{l}\text { Video/audio, question- } \\
\text { naire }\end{array}$ \\
\hline Sinatra et al. (2012) & $\begin{array}{l}\text { Adults: } n=111(75 \mathrm{~F}) \text {, } \\
18-26 \text { years }\end{array}$ & $1(5 \min )$ & ERS-7 & Dog, Cat, Legobot & Video, audio \\
\hline Weiss et al. (2009) & $\begin{array}{l}\text { Children: } n=129(70 \mathrm{~F}) \text {, } \\
\text { 3-15 years } \\
\text { Adults: } n=18(6 \mathrm{~F}), \\
\text { 21-68 years }\end{array}$ & $1(1-20 \mathrm{~min})$ & ERS-7 + ball \& bone & No control & $\begin{array}{l}\text { Video, observation, } \\
\text { questionnaire }\end{array}$ \\
\hline
\end{tabular}

$n$ number of participants, $f$ female, $\min$ minutes, N/A not applicable 
over-simplify their animistic preconceptions about living animals in comparison to older children-indicating that children progressively recategorize the robot as they discover distinct details about how technology varies from living objects (Okita and Schwartz 2006). Furthermore, when comparing attitudes toward AIBO and other robots, children perceive AIBO as a "robotic companion animal" (whereas adults interpret it to be less similar to dogs but more to machines) and use pronouns such as "s/he" instead of "it" when communicating with AIBO-indicating that children see aspects of the animal and the machine in this novel technical artifact based on their concepts and language formations (Bartlett et al. 2004).

Another study showed parallel patterns in preschoolage children thinking about AIBO and a stuffed dog: biological properties (46\%), moral standings (63\%), mental states (66\%), and social rapports (76\%) (Kahn et al. 2006). Compared to the "stuffed dog," however, children differ in their interpersonal encounters with AIBO by engaging in more exploration and hesitant behavioral habits, attempts at reciprocity, and less mistreatment of AIBO after an initial play session. Moreover, user experience was examined in an online questionnaire-based study through the lens of several key criteria: gender, age, culture, and length of ownership (Kertész and Turunen 2019). Women are more likely to ascribe emotional value to AIBO, while men are more attentive to the technological aspects of ownership. Although age plays no major part in the perception of the robotic dog, older age groups use more "negative" descriptors when describing AIBO. Within the scope of this study, Westerners have an overall more positive view of robots, whereas the Japanese have more concerns about the robots' role in society. AIBO owners did not experience a decrease in utility value over time-indicating that emotional attachment could play a role in their perception of AIBO.

One investigation revealed that when children were visited for 11 weeks (once in a week) first with a live dog and then with AIBO, no differences in contact initiation were observed between the two entities (Ribi et al. 2008). Over the observation period, the children more often initiated approaches to AIBO, whereas the live dog approached the children more often than AIBO. Overall, most children preferred the dog to AIBO and stroked it more frequently than AIBO, but the dog was less often touched than AIBO. In another study, comparing the natural, free form of communication while interacting with robotic artifacts such as Legobot and AIBO in comparison to live animals, such as a cat and dog, adults did not prefer live entities as a default because AIBO was often rated and communicated with similarly to the cat, although overall the dog was considered more competent and directly addressed more compared to the cat and the artifacts (Sinatra et al. 2012). Further, adults were less positive toward AIBO when framed as a puppy instead of a robot, and it was considered less "scary" after being dressed in a fur suit compared to having no fur (Schellin et al. 2020). Although adult reactions during encounters with a live and robotic dog appear identical, they assign more desirable traits (e.g., affectionate, responsive) and apply a higher voice level for commands when they think that they are leading a live dog instead of AIBO through a labyrinth (Pepe et al. 2008). Finally, both children and adults terminated T-patterns (i.e., a complex repeated temporal pattern for completing a given task for human-dog interactions) more frequently due to AIBO's slower movement when playing freely compared to a live puppy (Kerepesi et al. 2006).

Evaluating the perceived relationship with AIBO, most consumers (70-80\%) have a close bond to their robotic companion animal, and a decent number of owners (33\%) continue playing with AIBO in their daily lives (Fujita 2004). Further, about $26 \%$ of users consider AIBO as a playmate, and about $42 \%$ have feelings toward AIBO-indicating that the attachment between users and their robotic dogs is comparable to the bond owners have with their living dogs (Weiss et al. 2009). In assessing emotional attachment, children have more positive attitudes toward AIBO in comparison to adults: they assign more cognitive abilities (e.g., AIBO can see [76\%] and understand [78\%] them, has emotional feelings (e.g., AIBO may be happy [99\%] or sad [87\%]), attachment (e.g., AIBO could be a playfellow [91.6\%] and a companion while alone at home [90.2\%)]). Finally, over a month of research, the impact of AIBO's long-term artificial development on owners' sense of social presence and reactions was examined. The capacity of AIBO to evolve from a "puppy" to a "dog" enhanced the understanding of AIBO as a living being and resulted in higher feelings of social engagement and reactions toward AIBO (Lee et al. 2005).

In summary, users characterize their relation to AIBO to some degree in an analogous way as to a living dog, assign animal traits to it, treat it as a social "friend," and regard it as part of the family, a key assessment for human-animal attachment. However, when examining the behavior of owners, the studies revealed that they respond somewhat differently while interacting with AIBO or a living dog and regard it as a technological artifact that embodies characteristics of living animal species. AIBO's interactive capacities allow the robotic companion animal to appear to behave intentionally, which leads to mental characteristics and attributions-starting from essence and advancing to an agency, over social to moral standing (Kahn Jr et al. 2002). AIBO fulfills animistic biological underpinnings (e.g., referring to its embodiment and behaviors similar to real companion animals), agency properties (e.g., attributing intentions, feelings, emotional states, wishes, desires, and goals), social standings (e.g., ascribing an emotional connection and 
companionship), and moral standings (e.g., holding morally accountable for actions). The studies indicate that a new technology category is arising-children are constructing new conceptual categories for personified artifacts-that challenge conventional ontological genres. Based on those research findings, future HRI studies should focus specifically on the feelings of social presence and emotional attachment when building social robots.

The reported studies had limitations in terms of design and methodology. Most investigations were underpowered and unbalanced for gender (Ioannidis 2005; Kerepesi et al. 2006; Ribi et al. 2008; Sinatra et al. 2012). Further, various findings were restricted to single exposure observations, while the true value of those investigations would be increased if multiple exposures were included over a longer time frame. Moreover, little care has been made to track differences in the type of actions recorded for AIBO compared to a live dog, and in most cases, the activities for both agents were not recorded. Also, little effort was made to manage differences in familiarity and experience that might trigger differences in approach or resistance behavior for either the robotic agent or animal agent. Last but not least, although most experiments contrasted an experimental (AIBO) with a control condition (live dog), the observed disparities between the two agents relied on different dependent variable measures used to capture the agents' behavior.

These experiments and surveys offer a foundation for future investigations comparing a social human-robot with human-dog interactions and evaluating attitudes toward robotic agents as an antecedent to forming attachments by self-reported measures, behavioral analysis, and hormonal measures. For example, a more effective approach would be to compare differently behaving AIBOs (Okita and Schwartz 2006) rather than contrasting AIBO with a real dog as owners can differentiate between AIBOs that either behave "introvertly" or "extrovertly" after play (Lee et al. 2006). Moreover, more long-term experiments are needed to expose social robots' daily functionality and limitations (Kidd and Breazeal 2006). Finally, teaching techniques for autonomous robots could be applied. A promising technique for teaching behavioral sequences and uncommon behaviors for robotic companion animals include robotic clicker training - a technique used by animal trainers to direct animals toward specific activities (e.g., Kaplan et al. 2002). This type of training provides a clear demonstration of how robotics may benefit from ethology.

\section{Studies investigating animal-assisted therapy with AIBO}

In the United States, approximately 75 percent of households with children under the age of 18 have domestic companion animals-making dogs and/or cats a significant contributor to these children's ecological growth (Melson et al. 2009). A plethora of medical and psychological literature exists that demonstrates the benefits of having a companion animal, such as enhancement of social-emotional skills and empathy toward others (Ribi et al. 2008). Further, the formation of a bond with a companion animal is favorably linked with increased self-esteem in kindergarten children (Bergesen 1989). Children who own a companion animal have a more favorable view of companion animals in general (Beck et al. 1989). Animal lovers, for instance, are less likely to feel isolated and distressed and more likely to have satisfying relationships with others (Sparrow 2002). Interacting with companion animals leads to an acute, physiologically calming state of relaxation that makes owners happier, and improves their psychological and physiological well-being (Sparrow 2002). Owners need to take their companion animals to regular checkups, walks, and grooming-those chores provide ways to socialize with other people and help to reduce the feelings of loneliness and social isolation. However, it should be noted that there are many studies with opposite outcomes than the ones highlighted above, including increased BMI in pet owners, lowered survival rates after a cardiovascular event, and higher reported incidence of depression, anxiety, and other disorders (Koivusilta and Ojanlatva 2006; Müllersdorf et al. 2010; Parslow et al. 2005). Despite these findings, the majority of owners report they benefit from ownership and the relationship forged with their companion animal (Herzog 2011). The inconclusive results of many of these studies could be explained by poor methodological rigor, small and homogenous sample sizes, and small effect sizes (Ioannidis 2005).

Owing to the fact that companion animal owners believe that the mutual attachment improves health and psyche, animal-assisted therapy (AAT) has become a popular form of therapy (Tamura et al. 2004), in which children, elderly, and patients engage with companion animals in the form of recreation or therapeutic care. The effectiveness of AAT in healing includes physiological (e.g., improved blood pressure), psychological (e.g., reduced depression symptoms), cognitive (e.g., improved memory), and socio-emotional (e.g., improved communication with others) effects (Fujita 2004). A meta-analysis of AAT finding found moderate effects for improving autistic, medical, and psychological symptoms (Nimer and Lundahl 2007). In contrast, animal health concerns, varying cultural beliefs about animals, uncertainties, and liability problems are drawbacks to AAT (Melson et al. 2009). Further, AAT requires trained animals and a licensed caregiver, which most hospitals, nursing homes, or residential care centers providing physical, occupational, rehabilitation, or recreational therapy often cannot afford (Tamura et al. 2004). Instead of real animals, entertainment robots can be used to treat patients by implementing robot-assisted therapy (RAT) (Fujita 2004). In contrast 
to AAT, RAT has several advantages for robotic dogs such as AIBO: cleanliness, safety, low noise level, more robust workload, low costs, and no companion animal-loss (Fujita 2004; Miklósi and Gácsi 2012).

Indeed, robot-assisted activities have already been applied in several cases, including reducing loneliness in elderly care, mitigating stress and fatigue in workplaces, and promoting therapies for vulnerable social groups (Schellin et al. 2020). Especially, AIBO-assisted therapy has been implemented as a catalyst for stimulating socio-emotional functioning, attachment, and psychological well-being among elderly feeling lonely (Banks et al. 2008) and patients with schizophrenia (Narita et al. 2016), dementia; (Kimura et al. 2010; Tamura et al. 2004), and autism spectrum disorder (ASD) (François et al. 2009; Stanton et al. 2008) (Table 2).

Loneliness is a subjective perception regardless of objective assessments or outside opinions caused by predisposing factors (e.g., personality, beliefs, status) and precipitating events (e.g., divorce, disease, unemployment) (Banks et al. 2008). Visits with an AAT animal (as infrequent as once per week) can reverse loneliness to some degree. Even though the process by which AAT leads to reduced loneliness remains unknown, human bonding to the AAT animal is one potential explanation. A fascinating trend is the usage of robotic companion animals-particularly for people in Western countries whose lifestyles are not conducive of caring for a biological dog. One study contrasted AIBO and a live dog's ability to alleviate loneliness in a long-term care center. Elderly residents interacting with both dogs showed a reduction in loneliness in comparison to residents not receiving AAT (Banks et al. 2008). High levels of attachment in both dogs were observed in residents; however, psychological measures of attachment did not predict a reduction in loneliness-highlighting the fact that attachment cannot be the only process by which AAT changed loneliness. Another study suggests that AIBO-assisted therapy, broadly termed robot-assisted therapy (RAT), maybe also effective for schizophrenic patients - enhancing socialization, socio-emotional functioning, and therefore reducing loneliness and overall well-being (Narita et al. 2016).
With people living longer, the number of geriatric patients with severe dementia is increasing. The population of older individuals from the United States is estimated to rise to 80 million by 2050 , potentially contributing to an accelerated rate of dementia (Kramer et al. 2009). Dementia patients ultimately lose their short-term memory while maintaining long-term memory-increasing challenges in keeping communication with the outside world. While AAT services were developed as rehabilitation opportunities for long-term care patients, some of these facilities might be hesitant to offer AAT due to concerns regarding disease, cleanliness, or animal safety. Robotic dogs (e.g., AIBO) may encourage social communication among dementia residents without the disadvantages of encounters with a live dog. One investigation examined the impact of visitation by a human, a human escorted by a living dog, and a human escorted by AIBO on outcome measures of social encounters (e.g., touch, visual observation, and communication) for female women with dementia residing in a nursing home (Kramer et al. 2009). Human joined by a live dog and AIBO induced more social encounters than a human visit alone, and AIBO triggered more looks and contact than the dog-suggesting that RAT stimulating social interaction in dementia may be a realistic solution to live animal visits.

Another investigation collected electroencephalogram (EEG) measurements on a group of dementia patients in a nursing facility and a group of normal healthy controls to calculate the positive impact of RAT using a robotic dog (AIBO) (Kimura et al. 2010). Improvement of neuroactivity was detected in the dementia patients compared to healthy controls after 15 min of RAT based on EEG recordings (i.e., alpha bipolarity as an index of a brain function of loss of uniformity of an alpha wave distribution) performed in resting state for five minutes before and after RAT. Finally, another study compared the effectiveness of AIBO with a battery-driven toy dog at a health care facility housing patient with severe dementia (Tamura et al. 2004). Instead of traditional AAT, AIBO was used in occupational therapy to help dementia patients to remember emotions and memories combating short-term memory loss. Increased social contact

Table 2 Studies investigating robot-assisted therapy with the robotic dog AIBO

\begin{tabular}{llllll}
\hline Study & Participants & Exposure & AIBO model & Control & Measure \\
\hline Banks et al. (2008) & Adults: $n=38$, loneliness & $8(30 \mathrm{~min})$ & ERS-210A & Dog & Questionnaire \\
François et al. (2009) & Children: $n=6,4-11$ years, ASD & $10(30 \mathrm{~min})$ & ERS-7 & No control & Video \\
Kimura et al. (2010) & Adults: $n=15,60-97$ years, dementia & $2(15 \mathrm{~min})$ & ERS-7 & Remote controlled & EEG \\
Kramer et al. 2009 & Adults: $n=18(18 \mathrm{~F})$, dementia & $1(3 \mathrm{~min})$ & ERS-7 & Large-sized dog & Video \\
Narita et al. (2016) & Adults: $n=3(2 \mathrm{~F})$, schizophrenia & $8(20 \mathrm{~min})$ & ERS-210+ball & No control & Questionnaire \\
Stanton et al. (2008) & Children: $n=11(1 \mathrm{~F}), 5-8$ years, ASD & $1(30 \mathrm{~min})$ & ERS-210+ball & Mechanical toy dog & Video \\
Tamura et al. (2004) & Adults: $n=13(12 \mathrm{~F})$, dementia & $2(5 \mathrm{~min})$ & ERS-312 & Stuffed dog & Video \\
\hline
\end{tabular}

$n$ number of participants, $f$ female, $\min$ minutes, $A S D$ autism spectrum disorder, $E E G$ electroencephalography 
was found in both dogs' presence; however, patients had difficulty connecting emotionally with AIBO (i.e., recognizing that AIBO was a robot) without the intervention of a therapist. Overall, those studies demonstrated that implementing AAT strengthened communication between patients with dementia and AIBO.

ASD is a prevalent developmental disorder portrayed by the following three manifestations: inadequate social interaction (e.g., focus on objects instead of people, poor social skills, social withdrawal), diminished communication (e.g., lack of spoken language, atypical mannerisms, and verbal patterns) and presence of repetitive habits and restrained ambitions (e.g., repeated motor movements, use of items in an inoperative, repeated fashion) (Stanton et al. 2008). Pioneering HRI studies suggested that robots could help to minimize any of these manifestations. Different types of robotic therapeutic agents might help in different ways in the therapy of children with autism-addressing not only bodily and physical, but also emotional attachment and social interactions (Yun and Yoon 2018). A preliminary long-term study in a school setting investigated the possible application of robotic companion animals to assist children diagnosed with ASD to minimize some of their social deficits (François et al. 2009). An instructor-guided by principles of non-directive play therapy-took part in the social interactions, while the autistic children played with AIBO as the leading participant. Based on case-study evaluations, a progressive improvement was reported for the children for at least one category (i.e., affect, reasoning, play) over the sessions. Children who initiated social play enjoyed higher degrees of play, reasoned more about the robot, and occasionally expressed positive interest toward the robot. The encouraging findings for this innovative method-including planning, performing, and evaluating robot-assisted playare promising to become part of conventional therapy for ASD. Another investigation examined whether a robotic dog could assist in the improvement of social competences in ASD-diagnosed children (Stanton et al. 2008). Compared to a simple mechanical toy dog, children are engaged in more behaviors (e.g., communication, cooperation) with AIBO. However, no differences were found for animating and showing affection for AIBO.

In summary, encouraging preliminary evidence exists that AIBO as an autonomous robotic dog may promote attachment helping to relieve loneliness in elderly people (Banks et al. 2008), stimulate social interactivity and socioemotional functioning in schizophrenic patients (Narita et al. 2016), dementia (Tamura et al. 2004), and ASD (François et al. 2009; Stanton et al. 2008). Nevertheless, social robots still have restricted receptive and engaging capacities, potentially stagnating attachment bonds between humans and robots. Future studies should overcome the methodological and statistical shortcomings of those preliminary studies (e.g., lack of well-powered gender-balanced target populations, matched control conditions and groups, and absence of inferential statistical testing). As long as people consider robots to be social, RAT is devoted to an alternate approach where cleanliness, safety, and animal welfare could replace AAT with live animals. Importantly, robot-animal activities may become especially relevant given the current mass social distancing procedures practiced due to the global COVID-19 pandemic.

\section{Outlook—what does it mean for HRA?}

Despite substantial advances in designing persuasive social robots, caution is required in drawing conclusions based on the reviewed study results of RAT. The emerging category of robotic companion animals is in a position where hypothesis-driven investigations are needed to address obvious shortcomings and potentially facilitating HRA. Previous HRIs' studies with dog-like ethorobots have focused primarily on short- but not long-term social interactions that explore dynamic change in behavior and development of attachment over time. Further, little effort has been shown so far in studying the consequences of a robot's physical or socio-cognitive developmental abilities-being one of the essential features of social living creatures. There is no question that robots with evolving skills will have a greater influence on social interactions and will elicit more human socio-emotional feedback. Moreover, little is known about group-based HRIs since current research examines primarily individual interactions with social robots. Robots are most commonly expected to assist groups of people, such as in public places (e.g., shopping malls, airports) (Burgard et al. 1999; Nourbakhsh et al. 1999). Group-driven HRIs are expected to yield lower degrees of social replies and participation than individual-driven HRIs.

HRIs and HRA may be affected not only by the robot's design but also by demographic elements such as age, gender, and experiences with technology. Social robots have to be designed and built that consider these factors so that the HRIs are beneficial and attachment bonds are possible to a range of targeted individuals. For instance, the development of personas exhibiting human behaviors and traits may be applied in the development of subject-focused HRI and attachment applications (dos Santos et al. 2014). Also, robotic dogs may be used as social partners for other species. Employing animal-like robots may provide new ways of studying animal-robot interactions if the animal recognizes the autonomous robot as a social companion. Preliminary research has shown that while dogs respond much quicker than AIBO, improving appearance and speed may make it more desirable as a social partner (Kubinyi et al. 2004). As the development of robotic companion animals is only at the 
beginning, AIBO is the initial significant effort to build a profitable autonomous robot that can communicate socially and bond with humans.

However, no breakthroughs have been seen so far to invent a robotic companion animal that might genuinely function as a "real" animal in daily life. To accomplish this goal, social robots would have to pass the "Turing test" of social attachment (Kaplan 2001). Robots must display artificial attachment for being capable of creating and maintaining a fulfilling companionship with their owners. The "Turing test" requires social robots completing the Ainsworth Strange Situation Test to unveil their attachment style (Ainsworth 1969). While this test can inform whether the social robot is exhibiting attachment-type behavior, it does not determine whether the human owner perceives attachment toward the social robot. This could be achieved by implementing functional magnetic resonance neuroimaging (fMRI) to look at the attachment system in the human brain. Specifically, neural activation signatures of the human-dog attachment system could be characterized by scanning humans and dogs simultaneously in different MRI machines while they interact with each other-utilizing recently demonstrated awake canine imaging procedures (Jia et al. 2014; Ramaihgari et al. 2018; Robinson et al. 2016; Strassberg et al. 2019; Thompkins et al. 2018). Such findings could then be used as an alternate "Turing test" to prove whether social ethorobots activate this system in the human brain, which is also activated by their canine companion animals.

In the near future, robotic companion animals will become more technologically advanced, eliciting more human psychological reactions. Therefore, the social implication of artificial companion animals has still further to be explored: for instance, are they teaching children to nurture or to waste empathy on robotic animals that should be invested in human beings? It is possible a child may not experience the same benefits associated with companion animal care with the adoption of robotic companion animals without the moral obligations of genuine cooperation and companionship. It is not clear whether children will suffer from "nature-deficit disorder" (Louv 2008), but the social implications revealed by future research will be relevant to society. Furthermore, future research on HRI, especially HRA, will need to account for the moral dimensions of human interactions. Moral psychology, for example, has demonstrated that children develop notions of fairness, reciprocal care, and justice not only via human-human but also via human-animal partnerships (Friedman Jr. et al. 2003).

The evolution of artificial companion animals will occur in an environment of market forces and technological development with a current trend of more complex "intelligent" companion animals that are designed as robotic creatures to develop a long-term attachment with their owners. It will be interesting to see what qualities of live animals are replicated in these artificial beings, and what unique features are developed for them-a progression that will provide a unique viewpoint on the co-evolution of humans and domesticated animals. The reviewed literature reinforces the significance of a transdisciplinary framework for designing and building social ethorobots. Fascinating and significant findings can be accomplished by bridging the fields of robotics, psychology, and ethology so that social robots can provide not only emotional support but also satisfy therapeutic demands. In the foreseeable future, robotic companion animals will challenge traditional boundaries-expanding our understanding of relationship, friendship, and companionship — and continue to substitute our encounters with real companion animals. Ultimately, studying HRA will encourage us to learn more about ourselves.

Funding FK was supported by a MINERVA grant (FA9550-18-10455). GD and JSK are supported in part by the Defense Advanced Research Projects Agency (government contract/grant number W911QX-13-C-0123) for their dog-related research. The views, opinions, and/or findings contained in this article are those of the authors and should not be interpreted as representing the official views or policies, either expressed or implied, of the Defense Advanced Research Projects Agency, US Department of Defense, or the federal Government of the US.

\section{Compliance with ethical standards}

Conflict of interest The authors are unaware of any conflicts of interest, financial, or otherwise.

\section{References}

Abdai J, Korcsok B, Korondi P, Miklósi Á (2018) Methodological challenges of the use of robots in ethological research. Anim Behav Cogn 5:326-340

Ainsworth MDS (1969) Object relations, dependency, and attachment: a theoretical review of the infant-mother relationship. Child Dev 40:969-1025

Albert A, Bulcroft K (1988) Pets, families, and the life course. J Marriage Family 50(2):543-552. https://doi.org/10.2307/352019 (JSTOR)

Archer J, Ireland JL (2011) The Development and factor structure of a questionnaire measure of the strength of attachment to pet dogs. Anthrozoös 24(3):249-261. https://doi. org/10.2752/175303711X13045914865060

Banks MR, Willoughby LM, Banks WA (2008) Animal-assisted therapy and loneliness in nursing homes: use of robotic versus living dogs. J Am Med Direct Assoc 9(3):173-177. https://doi. org/10.1016/j.jamda.2007.11.007

Baron-Cohen S, Campbell R, Kamiloff-Smith A, Grant J, Walker J (1995) Are children with autism blind to the mentalistic significance of the eyes? Br J Dev Psychol 13:379-398

Bartlett B, Estivill-Castro V, Seymon S (2004) Dogs or robots: Why do children see them as robotic pets rather than canine 
machines? Proc Fifth Conf Aust User Interface-Volume 28:7-14

Bartneck C, Suzuki T, Kanda T, Nomura T (2007) The influence of people's culture and prior experiences with Aibo on their attitude towards robots. AI Soc 21(1-2):217-230

Beck A, Katcher AH, Aoki R (1989) The influence of pets in the ability of children to recognize emotional signals in humans and animals. In: Proceedings 5th International Conference on the Relationship between Humans and Animals, pp 15-18

Becker-Asano C, Ogawa K, Nishio S, Ishiguro H (2010) Exploring the Uncanny Valley with Geminoid HI-1 in a real-world application. In: Interfaces and human computer interaction, IADIS Intl, pp 121-128

Bensky MK, Gosling SD, Sinn DL (2013) Chapter five-the world from a dog's point of view: a review and synthesis of dog cognition research. In: Brockmann HJ, Roper TJ, Naguib M, Mitani JC, Simmons LW, Barrett L (eds) Advances in the study of behavior, vol 45. Academic Press, Cambridge, pp 209-406. https ://doi.org/10.1016/B978-0-12-407186-5.00005-7

Bergesen, F. J. (1989). The effects of pet facilitated therapy on the self-esteem and socialisation of primary school children $[\mathrm{PhD}$ Thesis]. University of Witwatersrand.

Berryman J, Howells K, Lloyd-Evans M (1985) Pet owner attitudes to pets and people: a psychological study. Vet Rec 117(25-26):659661. https://doi.org/10.1136/vr.117.25-26.659

Billard A (2003) Robota: clever toy and educational tool. Robot Auton Syst 42(3):259-269

Birnbaum GE, Mizrahi M, Hoffman G, Reis HT, Finkel EJ, Sass O (2016) What robots can teach us about intimacy: the reassuring effects of robot responsiveness to human disclosure. Comput Hum Behav 63:416-423. https://doi.org/10.1016/j. chb.2016.05.064

Bloom T, Friedman H (2013) Classifying dogs' (Canis familiaris) facial expressions from photographs. Behav Proc 96:1-10. https ://doi.org/10.1016/j.beproc.2013.02.010

Bloom P, Veres C (1999) The perceived intentionality of groups. Cognition 71(1):B1-B9. https://doi.org/10.1016/S0010 $-0277(99) 00014-1$

Bowlby J (1972) Attachment: vol 1. Penguin Books

Breazeal C, Aryananda L (2002) Recognition of affective communicative intent in robot-directed speech. Autonomous Robots 12(1):83-104. https://doi.org/10.1023/A:1013215010749

Brooks R (2002) Humanoid robots. Commun ACM. https://doi. org/10.1145/504729.504751

Burgard W, Cremers AB, Fox D, Hähnel D, Lakemeyer G, Schulz D, Steiner W, Thrun S (1999) Experiences with an interactive museum tour-guide robot. Artif Intell 114(1-2):3-55

Clutton-Block J (1995) Origins of the dog: domestication and early history. The domestic dog : its evolution, behavior and interactions with people. Cambridge University Press, Cambridge, pp 7-20

Colgan PW (1983) Comparative social recognition (Book, 1983) [WorldCat.org]. https://www.worldcat.org/title/comparativ e-social-recognition/oclc/8826638

Cooper RP, Aslin RN (1990) Preference for infant-directed speech in the first month after birth. Child Dev 61(5):1584-1595

Csányi V (2000) The 'human behavior complex' and the compulsion of communication: Key factors of human evolution. Semiotica. https://doi.org/10.1515/semi.2000.128.3-4.243

Dautenhahn K (2007) Socially intelligent robots: dimensions of humanrobot interaction. Philos Trans R Soc B 362(1480):679-704

Dautenhahn K, Werry I (2004) Towards interactive robots in autism therapy: background, motivation and challenges. Pragm Cogn 12(1):1-35
Dautenhahn K, Ogden B, Quick T (2002) From embodied to socially embedded agents-implications for interaction-aware robots. Cogn Syst Res 3(3):397-428. https://doi.org/10.1016/S1389 $-0417(02) 00050-5$

Donath J (2004) Artificial pets: simple behaviors elicit complex attachments. The encyclopedia of animal behavior. Greenwood Press

dos Santos TF, de Castro DG, Masiero AA, Aquino Junior PT (2014) Behavioral persona for human-robot interaction: a study based on pet robot. In: Kurosu M (ed) Human-computer interaction advanced interaction modalities and techniques, vol 8511. Springer International Publishing, Berlin, pp 687-696. https ://doi.org/10.1007/978-3-319-07230-2_65

Duffy BR (2003) Anthropomorphism and the social robot. Robot Autonomous Syst 42(3):177-190. https://doi.org/10.1016/ S0921-8890(02)00374-3

Émond C, Lewis L, Chalghoumi H, Mignerat M (2020) A comparison of NAO and Jibo in child-robot interaction. In: Companion of the 2020 ACM/IEEE International Conference on HumanRobot Interaction, pp 192-194

Fernald A (1992) Meaningful melodies in mothers' speech to infants. In: Nonverbal vocal communication: comparative and developmental approaches. Editions de la Maison des Sciences de l'Homme, pp 262-282

Fitch WT, Huber L, Bugnyar T (2010) Social cognition and the evolution of language: constructing cognitive phylogenies. Neuron 65(6):795-814

Fong T, Nourbakhsh I, Dautenhahn K (2003) A survey of socially interactive robots. Robot Autonomous Syst 42(3-4):143-166

Fraley RC, Roberts BW (2005) Patterns of continuity: a dynamic model for conceptualizing the stability of individual differences in psychological constructs across the life course. Psychol Rev 112(1):60-74. https://doi.org/10.1037/0033-295X.112.1.60

Francis A, Mishra P (2009) Is AIBO Real? Understanding children's beliefs about and behavioral interactions with anthropomorphic toys. J Interact Learn Res 20(4):405-422

François D, Powell S, Dautenhahn K (2009) A long-term study of children with autism playing with a robotic pet: taking inspirations from non-directive play therapy to encourage children's proactivity and initiative-taking. Interact Stud 10(3):324-373

Friedman B, Kahn PH, Hagman J (2003b) Hardware companions?What online AIBO discussion forums reveal about the humanrobotic relationship. New Horiz 5:8

Friedman B, Kahn Jr, P, Hagman J (2003a) Hardware companions? What online AIBO discussion forums reveal about the humanrobot relationship, pp 273-280https://doi.org/10.1145/64261 1.642660

Fujita M (2004) On activating human communications with pet-type robot AIBO. Proc IEEE 92(11):1804-1813

Fujita M (2007) How to make an autonomous robot as a partner with humans: design approach versus emergent approach. Phil Trans R Soc 365:2-47

Gácsi M, Topál J, Miklósi Á, Dóka A, Csányi V (2001) Attachment behavior of adult dogs (Canis familiaris) living at rescue centers: forming new bonds. J Comp Psychol 115(4):423-431. https://doi.org/10.1037/0735-7036.115.4.423

Gácsi M, Szakadát S, Miklósi Á (2013) Assistance dogs provide a useful behavioral model to enrich communicative skills of assistance robots. Front Psychol 4:971-971. https://doi. org/10.3389/fpsyg.2013.00971

Gácsi M, Kis A, Faragó T, Janiak M, Muszyński R, Miklósi Á (2016) Humans attribute emotions to a robot that shows simple behavioural patterns borrowed from dog behaviour. Comput Hum Behav 59:411-419

Gaunet F, Massioui FE (2014) Marked referential communicative behaviours, but no differentiation of the "knowledge state" of humans in untrained pet dogs versus 1-year-old infants. 
Anim Cogn 17(5):1137-1147. https://doi.org/10.1007/s1007 1-014-0746-z

Gosling SD, Kwan VSY, John OP (2003) A dog's got personality: a cross-species comparative approach to personality judgments in dogs and humans. J Pers Soc Psychol 85(6):1161-1169. https://doi.org/10.1037/0022-3514.85.6.1161

Hare B, Tomasello M (2005) Human-like social skills in dogs? Trends Cogn Sci 9(9):439-444. https://doi.org/10.1016/j. tics.2005.07.003

Hecht J, Miklósi Á, Gácsi M (2012) Behavioral assessment and owner perceptions of behaviors associated with guilt in dogs. Appl Ani Behav Sci 139(1):134-142

Heider F, Simmel M (1944) An experimental study of apparent behavior. Am J Psychol 57(2):243-259. https://doi.org/10.2307/14169 50 (JSTOR)

Herath DC, Kroos C, Stevens C, Burnham D (2013) Adopt-a-robot: a story of attachment (Or the lack thereof). In: 2013 8th ACM/ IEEE International Conference on Human-Robot Interaction (HRI), pp 135-136. https://doi.org/10.1109/HRI.2013.6483538

Herzog H (2011) The impact of pets on human health and psychological well-being: fact, fiction, or hypothesis? Curr Direct Psychol Sci 20(4):236-239. https://doi.org/10.1177/0963721411415220

Hrdy SB (2000) Mother nature: maternal instincts and how they shape the human species. Ballantine Books.

Ichikawa T, Beppu W, Kovács S, Korondi P, Hashimoto H, Niitsuma M (2012) Ethologically inspired human-robot communication for monitoring support system in intelligent space. IFAC Proc Volumes 45(22):58-63. https://doi.org/10.3182/20120 905-3-HR-2030.00136

Immerman RS, Mackey WC (2003) Perspectives on human attachment (Pair Bonding): eve's unique legacy of a canine analogue. Evolut Psychol. https://doi.org/10.1177/147470490300100110

Ioannidis JPA (2005) Why most published research findings are false. PLOS Med 2(8):e124. https://doi.org/10.1371/journ al.pmed.0020124

Irvine L, Cilia L (2017) More-than-human families: pets, people, and practices in multispecies households. Sociol Compass 11(2):e12455. https://doi.org/10.1111/soc4.12455

Jia H, Pustovyy OM, Waggoner P, Beyers RJ, Schumacher J, Wildey C, Barrett J, Morrison E, Salibi N, Denney TS (2014) Functional MRI of the olfactory system in conscious dogs. PLoS ONE 9(1):e86362

Jones T, Lawson S, Mills D (2008) Interaction with a zoomorphic robot that exhibits canid mechanisms of behaviour. IEEE Int Conf Robot Autom 2008:2128-2133. https://doi.org/10.1109/ ROBOT.2008.4543521

Kahn Jr PH, Friedman B, Hagman J (2002) "I care about him as a pal" conceptions of robotic pets in online AIBO discussion forums. In: CHI'02 Extended Abstracts on Human Factors in Computing Systems, pp 632-633

Kahn PH, Friedman B, Perez-Granados DR, Freier NG (2006) Robotic pets in the lives of preschool children. Interact Stud 7(3):405-436

Kaminski J, Tomasello M, Call J, Brauer J (2009) Domestic dogs are sensitive to a human's perspective. Behavior 146(7). https://brill .com/view/journals/beh/146/7/article-p979_7.xml

Kanda T, Shiomi M, Miyashita Z, Ishiguro H (2009) An affective guide robot in a shopping mall. In: Proceedings of the 4th ACM/IEEE international conference on Human robot interaction. https://doi. org/10.1145/1514095.1514127?casa_token =5-h6FYZcb3kA AAAA:fcbEcI0i8JicnlGzsXRMQ8heNMHQy94HOt12aXTy ufLINb9Ptc9qhNqYzaZYrBAjXeXqrh_q4dN4

Kaplan F (2001) Artificial attachment: will a robot ever pass ainsworth's strange situation test. In: Proceedings of Humanoids, pp 125-132

Kaplan F, Oudeyer P-Y, Kubinyi E, Miklósi A (2002) Robotic clicker training. Robot Auton Syst 38(3-4):197-206
Kerepesi A, Kubinyi E, Jonsson GK, Magnússon MS, Miklósi Á (2006) Behavioural comparison of human-animal (dog) and humanrobot (AIBO) interactions. Behav Proc 73(1):92-99

Kertész C, Turunen M (2019) Exploratory analysis of Sony AIBO users. AI \& Soc 34(3):625-638

Kidd CD, Breazeal C (2006) Designing a sociable robot system forweight maintenance. In: CCNC 2006. 2006 3rd IEEE Consumer Communications and Networking Conference, 2006, vol. 1, pp 253-257. https://doi.org/10.1109/CCNC.2006.1593026

Kiesler S, Goetz J (2002) Mental models of robotic assistants. In: CHI '02 Extended Abstracts on Human Factors in Computing Systems, pp 576-577. https://doi.org/10.1145/506443.506491

Kimura R, Miura K, Murata H, Yokoyama A, Naganuma M (2010) Consideration of physiological effect of robot assisted activity on dementia elderly by electroencephalogram (EEG): estimation of positive effect of RAA by neuroactivity diagram. Proc SICE Ann Conf 2010:1418-1422

Koay KL, Lakatos G, Syrdal DS, Gácsi M, Bereczky B, Dautenhahn K, Miklósi A, Walters ML (2013) Hey! There is someone at your door. A hearing robot using visual communication signals of hearing dogs to communicate intent. In: 2013 IEEE Symposium on Artificial Life (ALife), pp 90-97. https://doi. org/10.1109/ALIFE.2013.6602436

Koivusilta LK, Ojanlatva A (2006) To have or not to have a pet for better health? PLoS ONE 1(1):e109. https://doi.org/10.1371/ journal.pone.0000109

Konok V, Korcsok B, Miklósi Á, Gácsi M (2018) Should we love robots?-The most liked qualities of companion dogs and how they can be implemented in social robots. Comput Hum Behav 80:132-142

Korondi P, Korcsok B, Kovacs S, Niitsuma M (2015) Etho-robotics: What kind of behaviour can we learn from the animals?-Science direct. IFAC Papers Online 48(19):244-255

Kosfeld M, Heinrichs M, Zak PJ, Fischbacher U, Fehr E (2005) Oxytocin increases trust in humans. Nature 435(7042):673-676

Kovács S, Vincze D, Gácsi M, Miklósi Á, Korondi P (2009) Interpolation based fuzzy automaton for human-robot interaction. IFAC Proc Volumes 42(16):317-322. https://doi. org/10.3182/20090909-4-JP-2010.00055

Kramer SC, Friedmann E, Bernstein PL (2009) Comparison of the effect of human interaction, animal-assisted therapy, and AIBO-assisted therapy on long-term care residents with dementia. Anthrozoös 22(1):43-57. https://doi. org/10.2752/175303708X390464

Kubinyi E, Miklósi A, Kaplan F, Gácsi M, Topál J, Csányi V (2004) Social behaviour of dogs encountering AIBO, an animallike robot in a neutral and in a feeding situation. Behav Proc 65(3):231-239. https://doi.org/10.1016/j.beproc.2003.10.003

Kubinyi E, Viryani Z, Miklosi A (2007) Comparative social cognition: from wolf and dog to humans I request PDF. Compar Cogn Behav Rev 2:26-46. https://doi.org/10.3819/ccbr.2008.20002

Kubinyi E, Turcsán B, Miklósi Á (2009) Dog and owner demographic characteristics and dog personality trait associations. Behav Proc 81(3):392-401. https://doi.org/10.1016/j.bepro c. 2009.04 .004

Lakatos G, Gacsi M, Konok V, Bruder I, Bereczky B, Korondi P, Miklósi A (2014) Emotion attribution to a non-humanoid robot in different social situations. PLoS ONE. https://doi.org/10.1371/ journal.pone.0114207

Lee KM, Park N, Song H (2005) Can a robot be perceived as a developing creature? Effects of a robot's long-term cognitive developments on its social presence and people's social responses toward it. Hum Commun Res 31(4):538-563

Lee KM, Peng W, Jin S-A, Yan C (2006) Can robots manifest personality?: An empirical test of personality recognition, social 
responses, and social presence in human-robot interaction. $\mathrm{J}$ Commun 56(4):754-772

Louv R (2008) Last child in the woods: saving our children from nature-deficit disorder. Algonquin Books

MacDorman KF, Ishiguro H (2006) The uncanny advantage of using androids in cognitive and social science research. Interact Stud 7(3):297-337. https://doi.org/10.1075/is.7.3.03mac

Marshall-Pescini S, Passalacqua C, Petrazzini MEM, Valsecchi P, Prato-Previde E (2012) Do dogs (Canis lupus familiaris) make counterproductive choices because they are sensitive to human ostensive cues? PLoS ONE 7(4):e35437. https://doi.org/10.1371/ journal.pone.0035437

Melson G, Kahn Jr P, Beck A, Friedman B, Roberts T, Garrett E (2005) Robots as dogs?: Children's interactions with the robotic dog AIBO and a live Australian shepherd, pp 1649-1652. https://doi. org/10.1145/1056808.1056988

Melson GF, Kahn PH, Beck A, Friedman B, Roberts T, Garrett E, Gill BT (2009) Children's behavior toward and understanding of robotic and living dogs. J Appl Dev Psychol 30(2):92-102. https ://doi.org/10.1016/j.appdev.2008.10.011

Miklósi A (2014) Dog behaviour, evolution, and cognition. OUP Oxford, Oxford

Miklósi Á, Gácsi M (2012) On the utilization of social animals as a model for social robotics. Front Psychol 3:75

Miklósi A, Topál J (2013) What does it take to become "best friends"? Evolutionary changes in canine social competence. Trends Cogn Sci 17(6):287-294. https://doi.org/10.1016/j.tics.2013.04.005

Miklósi Á, Korondi P, Matellán V, Gácsi M (2017) Ethorobotics: a new approach to human-robot relationship. Front Psychol 8:958

Morell V (2009) Going to the dogs. Science 325(5944):1062-1065

Mori M (1970) Bukimi no tani [the uncanny valley]. Energy 7:33-35

Müllersdorf M, Granström F, Sahlqvist L, Tillgren P (2010) Aspects of health, physical/leisure activities, work and socio-demographics associated with pet ownership in Sweden. Scand J Public Health 38(1):53-63. https://doi.org/10.1177/1403494809344358

Narita S, Ohtani N, Waga C, Ohta M, Ishigooka J, Iwahashi K (2016) A pet-type robot AIBO-assisted therapy as a day care program for chronic schizophrenia patients: a pilot study. Aust Med J (Online) 9(7):244-248. https://doi.org/10.4066/AMJ.2016.2666

Nguyen H, Jain A, Anderson C, Xu Z, Trevor A, Kemp CC (2008) El-E: an assistive robot that fetches objects from flat surfaces. 9

Nimer J, Lundahl B (2007) Animal-assisted therapy: a meta-analysis. Anthrozoös 20(3):225-238

Nourbakhsh IR, Bobenage J, Grange S, Lutz R, Meyer R, Soto A (1999) An affective mobile robot educator with a full-time job. Artif Intell 114(1-2):95-124

Okita SY, Schwartz DL (2006) Young children's understanding of animacy and entertainment robots. Int J Humanoid Rob 3(03):393-412

Ostrander EA, Wang G-D, Larson G, vonHoldt BM, Davis BW, Jagannathan V, Hitte C, Wayne RK, Zhang Y-P, Dog10K Consortium (2019) Dog10K: An international sequencing effort to advance studies of canine domestication, phenotypes and health. Natl Sci Rev 6(4):810-824. https://doi.org/10.1093/nsr/nwz049

Oudeyer P-Y, Kaplan F, Hafner V, Whyte A (2005) The playground experiment: task-independent development of a curious robot. In: Proceedings of the AAAI spring symposium on developmental robotics

Parslow RA, Jorm AF, Christensen H, Rodgers B, Jacomb P (2005) Pet ownership and health in older adults: findings from a survey of 2551 community-based australians aged 60-64. Gerontology 51(1):40-47. https://doi.org/10.1159/000081433

Pepe AA, Ellis LU, Sims VK, Chin MG (2008) Go, dog, go: maze training AIBO vs. a live dog, an exploratory study. Anthrozoös 21(1):71-83
Pineau J, Montemerlo M, Pollack M, Roy N, Thrun S (2003) Towards robotic assistants in nursing homes: challenges and results. Robot Auton Syst 42(3):271-281. https://doi.org/10.1016/S0921 -8890(02)00381-0

Podberscek AL, Gosling SD (2000) Personality research on pets and their owners: Conceptual issues and review. In: Companion animals and us: exploring the relationships between people and pets. Cambridge University Press, Cambridge, pp 143-167

Pongrácz P, Molnár C, Miklósi Á (2006) Acoustic parameters of dog barks carry emotional information for humans. Appl Anim Behav Sci 100(3):228-240. https://doi.org/10.1016/j.appla nim.2005.12.004

Prato-Previde E, Spiezio C, Sabatini F, Custance DM (2003) Is the doghuman relationship an attachment bond? An observational study using Ainsworth's strange situation. Behaviour 140(2):225-254. https://doi.org/10.1163/156853903321671514

Ramaihgari B, Pustovyy OM, Waggoner P, Beyers RJ, Wildey C, Morrison E, Salibi N, Katz JS, Denney TS, Vodyanoy VJ (2018) Zinc nanoparticles enhance brain connectivity in the canine olfactory network: evidence from an fMRI study in unrestrained awake dogs. Front Vet Sci 5:127

Reid PJ (2009) Adapting to the human world: dogs' responsiveness to our social cues. Behav Proc 80(3):325-333. https://doi. org/10.1016/j.beproc.2008.11.002

Ribi FN, Yokoyama A, Turner DC (2008) Comparison of children's behavior toward Sony's robotic dog AIBO and a real dog: a pilot study. Anthrozoös 21(3):245-256

Robinson JL, Baxi M, Katz JS, Waggoner P, Beyers R, Morrison E, Salibi N, Denney TS, Vodyanoy V, Deshpande G (2016) Characterization of structural connectivity of the default mode network in dogs using diffusion tensor imaging. Sci Rep 6:36851

Sanders CR (1993) UNDERSTANDING DOGS: Caretakers' attributions of mindedness in canine-human relationships. J Contemp Ethnogr 22(2):205-226. https://doi.org/10.1177/0891241930 22002003

Schellin H, Oberley T, Patterson K, Kim B, Haring KS, Tossell CC, Phillips E, de Visser EJ (2020) Man's new best friend? Strengthening human-robot dog bonding by enhancing the Doglikeness of Sony's Aibo. Syst Inf Eng Design Sympos (SIEDS) 2020:1-6

Schrum M, Park CH, Howard A (2019) Humanoid therapy robot for encouraging exercise in dementia patients. In: 2019 14th ACM/ IEEE International Conference on Human-Robot Interaction (HRI), pp 564-565

Serpell J, Serpell P, of H. E. and A. W. J. (1996) In the company of animals: a study of human-animal relationships. Cambridge University Press, Cambridge

Sinatra AM, Sims VK, Chin MG, Lum HC (2012) If it looks like a dog: the effect of physical appearance on human interaction with robots and animals. Interact Stud 13(2):235-262. https:// doi.org/10.1075/is.13.2.04sin

Soproni K, Miklósi A, Topál J, Csányi V (2002) Dogs' (Canis familaris) responsiveness to human pointing. J Comp Psychol 116(1):27-34

Sparrow R (2002) The march of the robot dogs. Ethics Inf Technol 4(4):305-318

Stanton CM, Kahn PH, Severson RL, Ruckert JH, Gill BT (2008) Robotic animals might aid in the social development of children with autism. In: 2008 3rd ACM/IEEE International Conference on Human-Robot Interaction (HRI), pp 271-278

Strassberg LR, Waggoner LP, Deshpande G, Katz JS (2019) Training dogs for awake, unrestrained functional magnetic resonance imaging. J Vis Exp 152:e60192

Syrdal DS, Koay KL, Gácsi M, Walters ML, Dautenhahn K (2010) Video prototyping of dog-inspired non-verbal affective communication for an appearance constrained robot. In: 19th 
International Symposium in Robot and Human Interactive Communication, pp 632-637. https://doi.org/10.1109/ROMAN .2010 .5598693

Székely T, Moore AJ, Komdeur J (2010) Social behaviour: genes, ecology and evolution. Cambridge University Press, Cambridge

Tachi S, Tanie K, Komoriya K, Abe M (1985) Electrocutaneous communication in a guide dog robot (MELDOG). IEEE Trans Biomed Eng 32(7):461-469. https://doi.org/10.1109/ TBME.1985.325561

Tamura T, Yonemitsu S, Itoh A, Oikawa D, Kawakami A, Higashi Y, Fujimooto T, Nakajima K (2004) Is an entertainment robot useful in the care of elderly people with severe dementia? J Gerontol Ser A 59(1):M83-M85

Thompkins AM, Ramaiahgari B, Zhao S, Gotoor SSR, Waggoner P, Denney TS, Deshpande G, Katz JS (2018) Separate brain areas for processing human and dog faces as revealed by awake fMRI in dogs (Canis familiaris). Learn Behav 46(4):561-573

Thunberg S, Rönnqvist L, Ziemke T (2020) Do robot pets decrease agitation in dementia patients? In: International Conference on Social Robotics, pp 616-627

Tinbergen N (1963) On aims and methods of ethology. Zeitschrift Für Tierpsychologie 20(4):410-433. https://doi. org/10.1111/j.1439-0310.1963.tb01161.x

Topál J, Miklósi Á, Csányi V, Dóka A (1998) Attachment behavior in dogs (Canis familiaris): a new application of Ainsworth's (1969) strange situation test. J Compar Psychol 219-229

Topál J, Gacsi M, Miklósi A, Viryani Z, Kubinyi E, Csanyi V (2005) Attachment to humans: a comparative study on hand-reared wolves and differently socialized dog puppies. Anim Behav 70(6):1367-1375

Topál J, Gergely G, Erddohegyi A, Gergely C, Miklósi A (2009) Differential sensitivity to human communication in dogs, wolves, and human infants I science. Science 325(5945):1269-1272

Turcsán B, Range F, Virányi Z, Miklósi Á, Kubinyi E (2012) Birds of a feather flock together? Perceived personality matching in owner-dog dyads. Appl Anim Behav Sci 140(3):154-160. https ://doi.org/10.1016/j.applanim.2012.06.004
Turcsán B, Szánthó F, Miklósi Á, Kubinyi E (2015) Fetching what the owner prefers? Dogs recognize disgust and happiness in human behaviour. Anim Cogn 18(1):83-94. https://doi.org/10.1007/ s10071-014-0779-3

Valsecchi P, Previde EP, Accorsi PA, Fallani G (2010) Development of the attachment bond in guide dogs. Appl Anim Behav Sci 123(1):43-50. https://doi.org/10.1016/j.applanim.2009.12.012

vonHoldt BM, Pollinger JP, Lohmueller KE, Han E, Parker HG, Quignon P, Degenhardt JD, Boyko AR, Earl DA, Auton A, Reynolds A, Bryc K, Brisbin A, Knowles JC, Mosher DS, Spady TC, Elkahloun A, Geffen E, Pilot M et al (2010) Genome-wide SNP and haplotype analyses reveal a rich history underlying dog domestication. Nature 464(7290):898-902. https://doi. org/10.1038/nature08837

Wada K, Ikeda Y, Inoue K, Uehara R (2010) Development and preliminary evaluation of a caregiver's manual for robot therapy using the therapeutic seal robot Paro. In: 19th International Symposium in Robot and Human Interactive Communication, pp 533-538

Walker J, Dale A, Waran N, Clarke N, Farnworth M, Wemelsfelder F (2010) The assessment of emotional expression in dogs using a Free Choice Profiling methodology. Anim Welf 19(1):74-84

Weiss A, Wurhofer D, Tscheligi M (2009) "I love this dog"-Children's emotional attachment to the robotic dog AIBO. Int J Soc Robot 1(3):243-248

Wood LJ, Zaraki A, Robins B, Dautenhahn K (2019) Developing kaspar: a humanoid robot for children with autism. Int J Soc Robot. https://doi.org/10.1007/s12369-019-00563-6

Yun J-H, Yoon H-S (2018) Research trends and considerations in the clinical use of robots for children with autism spectrum disorders. J Korea Converg Soc 9(3):153-163

Publisher's Note Springer Nature remains neutral with regard to jurisdictional claims in published maps and institutional affiliations. 